Elsevier Editorial System(tm) for The Lancet Manuscript Draft

Manuscript Number: THELANCET-D-18-02754R1

Title: Effectiveness of a brief group psychological intervention for women in a post-conflict setting in Pakistan: a cluster randomized controlled trial

Article Type: Article (Randomised Controlled Trial)

Corresponding Author: Professor Atif Rahman,

Corresponding Author's Institution:

First Author: Atif Rahman

Order of Authors: Atif Rahman; Muhammad N Khan; Syed U Hamdani; Anna Chiumento; Parveen Akhtar; Huma Nazir; Anum Nisar; Aqsa Masood; Iftikhar U Din; Nasir A Khan; Bryant A Bryant; Katie S Dawson; Marit Sijbrandij; Duolao Wang; Mark van Ommeren

Abstract: Background: Many women are affected by anxiety and depression after armed conflict in low and middle income countries, yet there are few scalable options for their mental health care. We aimed to evaluate the effectiveness of a brief group psychological intervention for women in a conflict-affected setting in rural Swat, Pakistan.

Methods: In a single-blind cluster randomised controlled trial, 34 community-clusters in 2 Union Councils of rural Swat were randomised equally to Intervention (group intervention with 5 sessions incorporating behavioural strategies facilitated by non-specialists) or control

(Enhanced Usual Care) groups. Consenting women residing in the participating clusters who scored $\geq 3$ on the General Health Questionnaire (GHQ-12) and $\geq 17$ on the World Health Organization Disability Assessment Schedule (WHODAS), were recruited. The primary outcome, combined anxiety and depression symptoms, was measured 3 months post-intervention with the Hospital Anxiety and Depression Scale (HADS). All assessors were masked and intention to treat analyses were done, using mixed models adjusted for covariates and clusters defined a priori. The trial was registered with ACTRN, No: ACTRN12616000037404.

Findings: 612 women were enrolled between January 11, 2016, and August 21, 2016. 288/306 (94\%) and 290/306 (95\%) women in the Intervention and Control groups, respectively, contributed primary outcome data. Women in the Intervention group had significantly lower mean total scores on the HADS than controls (10.01 v 14.75, adjusted mean difference -4.53, 95\% CI -7.13 to -1.92). Individual HADS anxiety scores (5.43 v 8.02, AMD -2.52, 95\% CI -4.04 to -1.01 ) and depression scores (4.59 V 6.73, AMD -2.04; 95\% CI -3.19 to -0.88 ) were also significantly lower in the intervention arm. No adverse events were reported in either group.

Interpretation: This group psychological intervention resulted in clinically significant reductions in anxiety and depressive symptoms at 3 months and may be a feasible and effective option for women with psychological distress in rural post-conflict settings. 
Funding: World Health Organization through a grant from the Office for Foreign Disaster Assistance. 


\section{Effectiveness of a brief group psychological intervention for women in a post-conflict setting in Pakistan: a cluster randomized controlled trial}

Professor Atif Rahman, Ph.D., University of Liverpool, Liverpool, UK

Muhammad Naseem Khan., Ph.D., Khyber Medical University, Peshawar, Pakistan

Syed Usman Hamdani, MBBS, Human Development Research Foundation, Islamabad, Pakistan

Anna Chiumento, Ph.D., University of Liverpool, Liverpool, UK

Parveen Akhtar, M Phil., Human Development Research Foundation, Islamabad, Pakistan

Huma Nazir, M Phil Human Development Research Foundation, Islamabad, Pakistan

Anum Nisar, M Phil, Human Development Research Foundation, Islamabad, Pakistan

Aqsa Masood, BS (Hons.), Human Development Research Foundation, Islamabad, Pakistan

Iftikhar Ud Din MSPH, Bacha Khan Medical College, Mardan, Pakistan

Nasir Ali Khan MPH, Human Development Research Foundation, Islamabad, Pakistan

Professor Richard A. Bryant, Ph.D., University of New South Wales, Sydney, Australia

Katie S. Dawson, Ph.D., University of New South Wales, Sydney, Australia

Marit Sijbrandij, Ph.D., VU University Amsterdam, The Netherlands

Professor Duolao Wang, PhD, Liverpool School of Tropical Medicine, UK

Mark van Ommeren, Ph.D., World Health Organization, Geneva, Switzerland.

\section{Corresponding author:}

Atif Rahman

Professor of Psychiatry

University of Liverpool

Institute of Psychology, Health \& Society

Block B, Waterhouse Building, 1-5 Dover Street, Liverpool L69 3BX

T:+44-7807106764 E:atif.rahman@liverpool.ac.uk 
Background: Many women are affected by anxiety and depression after armed conflict in low and middle income countries, yet there are few scalable options for their mental health care. We aimed to evaluate the effectiveness of a brief group psychological intervention for women in a conflict-affected setting in rural Swat, Pakistan.

Methods: In a single-blind cluster randomised controlled trial, 34 community-clusters in 2 Union Councils of rural Swat were randomised equally to Intervention (group intervention with 5 sessions incorporating behavioural strategies facilitated by non-specialists) or Control (Enhanced Usual Care) groups. Consenting women residing in the participating clusters who scored $\geq 3$ on the General Health Questionnaire (GHQ-12) and $\geq 17$ on the World Health Organization Disability Assessment Schedule (WHODAS), were recruited. The primary outcome, combined anxiety and depression symptoms, was measured 3 months postintervention with the Hospital Anxiety and Depression Scale (HADS). All assessors were masked and intention to treat analyses were done, using mixed models adjusted for covariates and clusters defined $a$ priori. The trial was registered with ACTRN, No: ACTRN12616000037404.

Findings: 612 women were enrolled between January 11, 2016, and August 21, 2016. 288/306 (94\%) and 290/306 (95\%) women in the Intervention and Control groups, respectively, contributed primary outcome data. Women in the Intervention group had significantly lower mean total scores on the HADS than controls $(10.01 \mathrm{v} 14.75$, adjusted mean difference $-4.53,95 \%$ CI -7.13 to -1.92$)$. Individual HADS anxiety scores $(5.43 \mathrm{v} 8.02$, AMD -2.52, 95\% CI -4.04 to -1.01) and depression scores (4.59 v 6.73, AMD - 2.04; 95\% CI 3.19 to -0.88 ) were also significantly lower in the intervention arm. No adverse events were reported in either group.

Interpretation: This group psychological intervention resulted in clinically significant reductions in anxiety and depressive symptoms at 3 months and may be a feasible and effective option for women with psychological distress in rural post-conflict settings.

Funding: World Health Organization through a grant from the Office for Foreign Disaster Assistance. 


\section{INTRODUCTION}

Recent decades have seen an escalation in global conflict characterized by the wilful destruction of civilian life and property. ${ }^{1}$ This pattern of warfare, engulfing many parts of the world today, is associated with long-term psychological sequelae, ${ }^{2,3}$ with some reports indicating a far greater impact on women. ${ }^{3}$ Epidemiological studies from conflict-affected areas in Pakistan found high rates of clinically significant psychological distress in women, ranging from $38 \%$ to $65 \%$, ${ }^{4,5}$ with no access to psychological services for the majority. ${ }^{4}$ Conflict not only creates a greater need for health care, but also makes it more difficult to obtain. Health systems are weakened, the movement of vulnerable populations, especially women, may be restricted, and families might view treatment for psychological problems as intrusive. ${ }^{2}$ Against the backdrop of poor social status and role restrictions for women in a patriarchal society such as the tribal Northern areas of Pakistan, the sequalae of conflict are likely to place a disproportionate psychosocial burden on women. ${ }^{4,5}$

There is an urgent need to develop, test and disseminate culturally appropriate and scalable psychological interventions in such settings. ${ }^{6}$ Guidelines developed by the World Health Organization recommend a range of interventions for non-specialised health care settings, including cognitive behavioural therapy, interpersonal therapy and stress management, delivered in individual or group formats. ${ }^{7}$ These guidelines are supplemented by reviews demonstrating that these interventions can be effectively delivered by non-specialist staff in Low and Middle Income Countries (LMIC). ${ }^{8,9}$ However, brief, evidence-based, transdiagnostic, group psychological interventions that can cater to a range of psychological conditions and contexts are not currently available in LMIC.

Previously, we evaluated the World Health Organization's Problem Management Plus $(\mathrm{PM}+),{ }^{10}$ an individually-administered intervention incorporating behavioural strategies, in one conflict-affected urban area of Pakistan, and found it to be culturally appropriate and feasible. ${ }^{11}$ This transdiagnostic intervention, tested in urban healthcare facilities, improved anxiety, depression, posttraumatic stress disorder (PTSD) symptoms and functioning compared to enhanced usual care (EUC) - with post-hoc analyses suggesting that effects were achieved independent of initial severity. ${ }^{11}$ There is substantial interest by a wide range of international humanitarian agencies to scale up PM+ (http://www.who.int/mental_health/emergencies/PM_plus_2018/en/).

However, the physical distance of rural communities from urban health-care facilities is a barrier to care - our feasibility study suggested that due to stigma, family resistance, and restrictions upon movement, only a fraction of women, especially those living in rural areas, could attend the intervention at urban care facilities.

To address this gap in Pakistan and elsewhere, a community-based group version of the intervention, delivered by female non-specialists working in partnership with local community health workers, was developed and successfully piloted in rural Swat. ${ }^{12}$ The aim of this cluster randomized clinical trial (cRCT) was to establish the effectiveness of this new WHO group intervention in a conflict-affected setting. We hypothesized that women assigned to the intervention would show greater reductions in symptoms of anxiety, depression, PTSD, and functional impairment, improved social support, and reduced rates of depressive disorder, at 3-months post-intervention compared with those randomized to EUC. 


\section{Settings and Study design}

The study was conducted in Swat District, Pakistan, which has an estimated population of about 2 million. Over $85 \%$ percent of the population lives in rural areas, with agriculture and tourism the main sources of income generation. From 2007 to 2011, Swat experienced a severe armed conflict between the Pakistani military and Taliban insurgents, displacing over 1.5 million people and causing significant damage to Swat's economy, infrastructure and social fabric. ${ }^{13}$ Over a third of health and educational facilities, and hundreds of businesses were destroyed. ${ }^{13,14}$ Sporadic violence since continued to have a negative impact on the well-being of the population. ${ }^{14}$ The post-conflict rehabilitation, reconstruction and recovery is still in progress.

The District of Swat has 65 Union Councils (UCs). The UC is the smallest rural administrative unit in Pakistan containing approximately 25,000 people, served by a primary healthcare (PHC) facility staffed by a physician, a midwife, a vaccinator, and 15-20 community-based Lady Health Workers (LHWs) including a supervisor. LHWs are community health workers, each responsible for a community-cluster of approximately 1,000 people or 150 homes, visiting five to seven homes daily.

This two-arm single-blind cluster RCT was conducted in two rural UCs of Swat, Odigram and Ghalegay, from January 11, 2016 to December 30, 2016. As the intervention was delivered through community-based groups, a cluster randomized design, with an LHW community-cluster as the unit of randomization, was used to minimize the risk of contamination of the control group with the intervention. Primary outcome was combined symptom score of anxiety and depression measured with HADS at 3 months post-intervention. Secondary outcomes were PTSD symptoms, functional impairment, problems for which the person sought help, perceived social support, and rates of depressive disorder.

The project was approved by the Institutional Review and Ethics Board of the Institute of Psychiatry, Rawalpindi Medical College, Pakistan; and by the WHO Ethical Review Committee (RPC705, version 4, November 2, 2015). The trial protocol is available online. ${ }^{15}$

\section{Randomisation and masking}

Individual LHW community-clusters across Odigram and Ghalegay UCs formed the units for randomization, each UC contributing 23 and 22 LHW community-clusters respectively. Of these 45 community-clusters, 11 were inaccessible or unstaffed by LHWs and were excluded (Fig 1). Randomisation of the remaining 34 communityclusters was done before the participants were approached for screening and enrolment. Permuted-block randomisation method was used to generate the randomisation code, with a block size of 6 . Allocation of clusters was carried out by an independent statistician based at the University of Liverpool using a computerized randomisation sequence.

It was not possible to mask participants or group facilitators to the intervention allocation. However, the researchers responsible for identifying, obtaining consent, enrolling trial participants, and conducting outcome assessments were masked to the 
allocation status. All assessors resided outside the study area, and had no interaction with the intervention team. Women were asked not to tell the interviewers about their group session, and all household members were reminded of this by the Lady Health Worker before each assessment visit. To elicit the success of the masking, outcome assessors were asked to guess the allocation status of each participant before the 3month assessment.

\section{Participants}

Participants were women in the 34 community-clusters who were aged 18-60 years, and intended to reside in the study area for the next 6 months. They were enrolled from January 11, 2016, to August 21, 2016. Lists of participants from each cluster were compiled from official registers kept with the LHWs. The research staff screened a random sample of potentially eligible residents until the desired enrolment number was reached. Women with severe mental disorder (e.g., psychotic disorders, substance dependence) or severe cognitive impairment (e.g., severe intellectual disability), or imminent suicide risk were excluded (Figure 1). All participants provided written informed consent to participate in the research.

Eligible participants who scored both (a) 3 or above on a screening questionnaire for common mental disorders (General Health Questionnaire-12; GHQ-12), ${ }^{16}$ and (b) 17 or above on a questionnaire for functional impairments (WHO Disability Assessment Schedule 2.0; WHODAS ${ }^{17}$ were invited to participate in the cRCT. The GHQ-12 evaluates psychological distress and has 12 questions scored on a 4-point Likert. When applied as a screener, it is scored bimodally (0-0-1-1). A cut-off of 3 or above has been used in previous validation studies in Pakistan and indicates likelihood of clinically significant distress. ${ }^{16}$ The WHODAS is a 12 -item interviewer-administered tool which assesses health-related difficulties across domains of functioning. Difficulties are scored on a 5-point scale over last 30 days, with a total score of 60 , and the cut-off score of 17 has been used in previous studies in Pakistan. ${ }^{11,12}$ Recruitment continued until 18 eligible women were recruited from each communitycluster.

\section{Procedures}

Intervention: The group intervention is an adaptation of a WHO individual intervention, Problem Management Plus (PM +$).{ }^{10}$ Group PM + consists of five weekly group sessions with approximately 6-8 participants per group, each session lasting approximately two hours (excluding breaks). The first session includes psychoeducation, goal setting, and brief motivational interviewing. Sessions one to four introduce strategies for stress management, problem solving, behavioural activation and strengthening social support. Each strategy is reviewed in every subsequent session, and the final session involves revision of learning, education on preventing relapse, and a closing ceremony. As many participants are non-literate, the intervention includes locally relevant pictorial materials and adopts a narrative format through sharing case examples of women experiencing common practical and emotional problems, with participants following their stories through the sessions. The groups, facilitated by local women, gives participants a safe space to share feelings and learn from each other's experiences, allowing a degree of empowerment and control over their lives as they problem-solve together. Each LHW provided logistical support by convening sessions in her house with participants from her 
catchment area. LHWs are mandated to provide one room in their house, referred to

The therapists, called facilitators, were local bachelor level graduates without mental health care experience. The facilitators received seven days of intervention training by a master trainer (KSD) and supported by three in-country supervisors based in Islamabad, Pakistan (PA, HN, AM). Intervention training included education on adversity and its impact upon mental health, basic helping skills, delivering the intervention strategies, skills in group facilitation, and facilitator self-care. All facilitators delivered one practice group each at an accelerated rate (five sessions in two weeks) with participants living outside the trial area and under intensive supervision (10 hours supervision over two weeks). All facilitators were assessed for their competency using a specially developed checklist that evaluated basic counselling skills and their use of intervention strategies through direct observation of specially designed role plays. Competency was rated using a 5-point Likert scale ranging from 0 (not done) to 4 (excellent). A score of 2 or higher on each item indicated competency. Six facilitators delivered the intervention to the trial participants. The facilitators received a small honorarium of USD100 per month.

Supervision of the facilitators was conducted through 2 hours of weekly group session by experienced Islamabad-based supervisors via Skype. In turn, the supervisors received 1.5 hours of fortnightly supervision via Skype by the master trainer in Sydney, Australia. Supervision included review of participants' progress and individual case-management, refresher training on strategies and rehearsing skills through role-play.

Intervention fidelity was monitored by independent observers of $15 \%$ of randomly selected sessions of each facilitator ( $\mathrm{N}=36 ; 6$ sessions per facilitator) against a checklist consisting of items capturing key intervention strategies for each session. The responses were recorded as yes or no for each given strategy for the particular session. Based on this evaluation, the supervisor rated the fidelity of each session overall as satisfactory or unsatisfactory. Weak areas identified were reinforced during supervision.

Enhanced usual care (EUC): EUC for all participants comprised the following: a) feedback about the assessment results; b) participants and their accompanying family members were offered psychoeducation and the opportunity to talk about their health with their LHW who received a half-day training programme in psychoeducation and supportive communication; and; c) information about the options for seeking care for distress (i.e. through their PHC center or the tertiary healthcare center). The PHC providers received a half-day training in the detection and management of mental health problems, and referral pathways for care.

\section{Outcomes}

The primary outcome assessed at the individual level was severity of anxiety and depressive symptoms measured using the Hospital Anxiety and Depression Scales $(\mathrm{HADS})^{18}$ (total HADS scores at 3 months post-intervention). The HADS is a 14 -item scale consisting of 2 sub-scales: HADS-A (anxiety, 7 items, range 0-21) and HADS$\mathrm{D}$ (depression, 7 items, range 0-21). Higher scores indicate more anxiety and/or depression symptoms. The HADS has been validated across cultures, including 
285 Pakistan, and found to have good reliability and validity. ${ }^{19}$ The minimal clinically 286 important difference has been determined at 1.32 for HADS-A and 1.40 for HADS-

Secondary outcomes, also measured at the individual level, included PTSD symptoms using the 20-item PTSD Checklist for DSM-5 (PCL-5). ${ }^{21}$ Items are rated 0 to 4 (total score range of 0-80). The PCL has shown good diagnostic accuracy and internal consistency and has been used in Pakistan. ${ }^{11}$ Functional impairment was measured through the WHODAS, which has shown good psychometric properties in terms of internal consistency, test-retest reliability, and agreement with other measures of disability across countries including Pakistan. ${ }^{17}$ The Psychological Outcome Profiles (PSYCHLOPS) $^{22}$ was used to measure progress on problems for which the person sought help. It covers 3 domains: problems (2 questions), functioning (1 question), and wellbeing (1 question). Responses are scored on an ordinal 6-point scale producing a maximum score of 20 (5 points per question). The PSYCHLOPS has shown satisfactory internal consistency, and good convergent validity with measures of psychological distress and sensitivity to change. Perceived social support was measured by the Multi-Dimensional Scale of Perceived Social Support, validated in South Asian women. ${ }^{23}$ Participants were assessed for likely depressive disorder with the Patient Health Questionnaire (PHQ-9). ${ }^{24}$ Participants rate their responses on a 4point scale ranging from "not at all" to "nearly every day." The PHQ-9 total score ranges from 0 to 27. The PHQ-9 has been validated in Urdu, showing good sensitivity and specificity. ${ }^{25}$ A cut-off score of 10 or above is used to estimate likely depressive disorder.

All outcome assessments were conducted by trained researchers who shared the same culture as the participants. Due to a large number of non-literate participants, questions were read out by the researchers who were trained to ask them in a uniform and standardised fashion. Information on severe adverse events including death of the participant due to any cause, suicide attempt, hospitalisation, stigmatisation, and reported violence were collected.

\section{Statistical analysis}

Community-based intervention studies using change in symptom-based questionnaires like the HADS have used effect sizes of at least 0.4 when testing treatment as usual groups with limited or no active therapeutic elements. ${ }^{11,26}$ Intracluster correlation (ICC) of 0.05 was used to allow for between-community-cluster correlation. This is a conservative estimate based on a previous study in a similar rural population, ${ }^{26}$ where ICC of $0.04-0.09$ was observed between union councils (which were the cluster units). We would expect a substantially lower ICC between community-clusters within a union council. Assuming an effect size of 0.4 for the primary endpoint (HADS total score at 3 months post-intervention), with $90 \%$ power and 5\% significance, an ICC of 0.05 , and a two-sided hypothesis test with 34 community-clusters randomised at a 1:1 allocation ratio, and accounting for $20 \%$ attrition, we required 612 participants (306 in each arm), or an of average 18 participants per cluster.

Primary analyses were intention-to-treat and included participants who were randomised and had at least one complete measurement of primary or secondary outcomes. A linear mixed model was employed for the primary endpoint analysis. 
The mixed model included treatment, visit, interaction between treatment and visit as fixed effects, baseline measurement of HADS as covariate, and cluster and subject as random effects. The mean difference between two treatment arms at each visit, together with its $95 \%$ confidence interval (CI), was derived from the mixed model. Covariate-adjusted mixed model of primary endpoint was also performed by adding three pre-specified covariates at baseline (age, WHODAS and PHQ scores) into the analysis and no imputation of primary endpoint was made. To assess the sensitivity of the result to this assumption, the last observation carried forward strategy was used to compute missing primary endpoints. Subgroup analysis was performed on the three pre-specified covariates.

Continuous secondary outcomes were analysed in a similar way as the primary endpoint analysis. For the analysis of binary secondary outcomes, a generalised linear mixed model was employed with treatment, visit, interaction between treatment and visit as fixed effects, baseline measurement as covariate, and cluster and subject as random effect. The odds ratio between two treatment arms at each visit together with its $95 \%$ CI was derived from the generalised mixed model. All analyses were described in detail in the finalized and signed statistical analysis plan before unmasking the study. Data were analysed using SAS 9.3 and SPSS Version 21.

\section{Role of funding source:}

The study is supported by a grant from the Office of Foreign Disaster Assistance (OFDA) to WHO and a small travel grant from the University of Liverpool Overseas Development Agency Seed Fund. The funding bodies had no role in the design and conduct of the study; collection, management, analysis, and interpretation of the data; preparation, review, or approval of the report. The corresponding author had full access to all the data in the study and had final responsibility for the decision to submit for publication.

\section{RESULTS}

Figure 1 depicts participant flow through the trial. From a list of 2565 potential participants 1745 women were randomly screened, and 612 women meeting the eligibility criteria were enrolled between January 11, 2016 and August 21, 2016. The primary outcome assessment point of 3 months post-intervention was available for 288/306 (94\%) of intervention group participants and 290/306 (95\%) of the control group. At one-week post-intervention the follow-up rates were 298/306 (97\%) and $300 / 306(98 \%)$ in the intervention and control groups respectively.

Of 612 participants, $503(83 \%)$ were non-literate, the mean (SD) age of the participants was 36.32 (9.78) years. There was no significant difference between the intervention and control group in demographic characteristics (Table 1).

Table 2 presents the findings of the primary and secondary outcomes at all timepoints. At baseline the intervention and control groups had similar scores on HADS total score 21.08(6.69) vs 21.83(7.30) as well as individual HADS scores of anxiety (mean [SD] 11.46[3.99] vs 11.71[3.95] and depression 9.62 [3.64] vs 10.12 [4.18]. At three months post-intervention, the intervention group had significantly lower score than the control group on HADS total score (mean [SD], 10.01[7.54] vs 14.75 

(5.43[4.18] vs. 8.02[4.69], AMD, $-2.52 ; 95 \%$ CI, -4.04 to -1.01 ) and depression symptom scores (4.59[3.87] vs. 6.73[3.91], AMD, -2.04; 95\% CI, -3.19 to -0.88) were also significantly lower in the intervention group. Similar differences were measured at 1-week post-intervention in HADS total scores (mean [SD] 10.58 [8.05], vs 17.00 [8.30], AMD, $-6.30 ; 95 \% \mathrm{CI},-8.89$ to -3.70$)$, as well as individual anxiety (5.84[4.58] vs 8.99 [4.70], AMD, $-3.14 ; 95 \%$ CI -4.64 to -1.63$)$ and depression scores (4.74[3.95] vs $8.01[4.21$ ], AMD, $-3.20 ; 95 \% \mathrm{CI},-4.35$ to -2.05 ).

At 3-months post-intervention, there were also significant reductions in WHODAS functional impairment scores (AMD -2.90; 95\% CI, -5.39 to -0.42), problems for which the person sought help (PSYCHLOPS score: AMD,-2.07; 95\% CI, -3.73 to 0.41 ), and symptoms of depressive disorder (PHQ-9 score: $-1.67 ; 95 \% \mathrm{CI},-3.16$ to $0.19)$.

Results with covariate adjusted analysis and Last Observation Carried Forward (LOCF) analysis are reported in Tables 3 and 4 respectively and are consistent with those reported in Table 2. Table 5 shows that age and initial severity of depression and impaired functioning did not influence the interventions effects on the HADS primary outcome.

At baseline, 137/306 (45\%) of participants in the intervention group and 171/306 $(56 \%)$ in the control group met the PHQ-9 criteria for depressive episode, while at 3 months post-intervention, $42 / 288(15 \%)$ and $87 / 290$ (30\%) participants in the intervention and control group, respectively, met the PHQ-9 criteria for depressive disorder (OR, $0.44 ; 95 \%$ CI, 0.20 to 0.95 ). Although significant differences were found in mean PTSD symptom scores at 1-week post-intervention (PCL-5 score AMD, $-3.44,95 \%$ CI $-6.15,-0.73)$, no significant differences were found on PTSD (AMD, -2.16 ; $95 \% \mathrm{CI},-4.88$ to 0.56 ).

The outcome assessors correctly guessed the allocation of 125 (44\%) of 287 in the EUC group compared with 158 (55\%) of 285 of in the intervention group prior to the primary outcome assessment at 3 months post-intervention, indicating that masking was successful.

Competency assessments following training found that all 6 facilitators who delivered the intervention scored 2 or more on all items of the basic counselling skills, group management skills and intervention strategies assessed. Of 36 sessions observed directly to evaluate intervention fidelity, $33(92 \%)$ were assessed as satisfactory.

A total of 255 sessions were conducted in 51 groups, with an average group size of $6 \pm 0.49$ (range 4 to 7 ). $251 / 306$ ( $82 \%$ ) of the participants attended 3 or more sessions. The mean [SD] number of sessions attended by the intervention participants was 3.80 (1.57). Average duration of a Group PM+ session was 2 hours \pm 15 minutes. Only 2 intervention arm participants attended the primary care centre for their psychological problems in the period of the study.

All EUC participants were provided psychoeducation consisting of feedback about their assessment result and informed about the options for seeking appropriate care. In the EUC arm, we documented 142 contact sessions of 89 participants with the 
LHWs, 141 contact sessions of 100 participants with the PHC physician and 6 contact psychotropic medicine was prescribed to any participant for the duration of study.

\section{DISCUSSION}

This study tested the effectiveness of a new WHO group intervention, delivered by non-specialists to women with psychological distress living in rural, conflict-affected Swat, Pakistan. Results showed significant reductions in symptoms of anxiety and depression, self-identified problems for which the women sought help, and rates of depressive disorder, measured at one week and at 3 months' post-intervention. Initial problem severity did not affect the outcomes. indicating the intervention is also helpful for those with severe problems.

These results are in keeping with the literature on group psychological interventions from High Income countries (HIC). A meta-analysis of 23 studies of group therapies in PHCs and the community found that group therapies were more efficacious for clinically depressed participants compared to usual care. ${ }^{27}$ However, most of these interventions were delivered by specialists or experienced practitioners. Furthermore, accepted guidelines such as the National Institute for Health and Clinical Excellence in the UK recommend 16-20 sessions over 3-4 months for high-intensity, and a minimum of 8 sessions for low-intensity interventions. To our knowledge, this is the first randomized trial to demonstrate the effectiveness of a brief 5-session group intervention delivered by local non-specialists for common mental disorders. The group format is likely to be attractive for communities where support networks are often communal but may have been disrupted in the aftermath of conflict. Brief group interventions are less resource-intensive per person helped than individual interventions, and are possibly more cost-effective. ${ }^{27}$ This trial should provide a policy impetus to include such interventions in post-conflict reconstruction and rehabilitation efforts.

In our previous study in primary care settings, the individually administered intervention led to sustained improvements in trauma symptoms in a mixed gender sample compared to controls ${ }^{11}$, while in the current study, these differences were significant at 1 -week post-intervention but not at 3 -months post-intervention. This may be a reflection of the differences in the study population - the current study was entirely women in a rural setting where the impact of the conflict was more diffused and baseline rates of post-traumatic stress symptoms were much lower in this study. Ongoing problems of living might contribute more to these women's distress compared to the mixed population presenting to peri-urban primary care centres whose symptoms might have been more directly related to trauma. Also, it is likely that persons with trauma symptoms benefit more of approaches that involve traumafocused emotional processing, which are key to the most effective PTSD treatments ${ }^{28}$, and which are not part of $\mathrm{PM}+$.

The results of this trial demonstrate the feasibility of employing local non-specialist graduates to deliver a transdiagnostic psychological intervention in this post-conflict setting. The apprenticeship and cascaded model of training and supervision ${ }^{29}$ was successfully implemented. Following the one-off 7-day classroom training, all subsequent supervision was conducted by off-site supervisors in a different city 
485 (Islamabad), who in turn were supervised by a master trainer in another country

486 (Australia). The group facilitators demonstrated satisfactory competence levels

487 following training, and fidelity to intervention protocols throughout the study. As the

488 use of technology for supervision from distance becomes more widespread ${ }^{30}$ such

489 models hold great promise in disseminating services in hard-to-access areas such as

490 conflict zones. The non-specialist graduates worked in partnership with the well-

491 established LHWs who convened and hosted the PM+ Groups. All groups were

492 successfully completed and attendance rates were high, demonstrating the cultural

493 acceptability and feasibility of this approach. Local facilitators are more likely

494 understand people's problems and be culturally sensitive compared to 'parachute'

495 therapists from outside the community. ${ }^{31}$

Despite being conducted in a post-conflict environment with sporadic ongoing violence, this community-based trial had a high response and follow-up rate. As far as possible, efforts were made to train local researchers who had a good understanding of community sensitivities and were not seen as outsiders. All recruitment and assessments were done by trained female research assistants from the same cultural background as the women participants. Involvement of local researchers has been identified as an important practical as well as ethical step to conducting research in conflict and post-conflict settings. ${ }^{32}$

Our study had several other strengths. The cluster design ensured that the risk of contamination was minimised. The baseline characteristics in the two groups were similar, and efforts to ensure that the assessors remained unaware of treatment group allocation were successful. Many participants showed an improvement in the enhanced usual care group. While this could be a consequence of regression to the mean, some contamination of the control group with elements of the intervention cannot be entirely ruled out as the participants attended the same health facilities and may have interacted. The intervention and EUC conditions differed on several variables, including number of sessions, the role of supervision, and importantly, group versus individual format. Although records were kept of number of contacts with health staff, details of what happened in the EUC contacts was not collected. Thus, we cannot exclude the explanation that significant symptom reduction in the control group could be attributed to unmeasured factors. In studies such as this it is not possible to keep the participants blind to the intervention and control conditions. Furthermore, the outcomes were based on self-report questionnaires. Both of these factors can potentially bias the results. Another limitation is the lack of a longer-term follow-up. Given the challenges of conducting research in such settings, the study results give hope that evidence-based interventions can be feasibly provided to populations living in the aftermath of conflict. Replication trials are being conducted to indicate the effectiveness of Group PM+ across settings and contexts. Such studies will also explore which component mediates effect, how long this lasts, and if additional sessions may be necessary to maintain effect.

In conclusion, given that a large number of women suffer from anxiety and depression following exposure to conflict, this brief group psychological intervention delivered in rural settings by local non-specialists can be effective in reducing the burden from these conditions. This WHO group intervention may increase the options that humanitarian agencies have to provide mental health support to rural women in Pakistan and globally. 


\section{Contributors:}

AR drafted the manuscript assisted by MNK, SUH and AC, and all authors reviewed and approved it. AR, SUH, MNK, RB, MS, AC and MvO were responsible for the design of the trial; $\mathrm{KD}, \mathrm{RB}, \mathrm{PA}, \mathrm{HN}, \mathrm{AN}, \mathrm{AM}, \mathrm{AC}$, and $\mathrm{MvO}$ were responsible for intervention content, training and supervision; MNK, SUH, IUD, NAK, MS, MvO and AR were responsible for trial conduct; DW, NS and SUH were responsible for database design and management; and DW was responsible for analyses; all authors contributed to the interpretation of the data.

\section{Declaration of Interests:}

The authors declare that they have no competing interests.

\section{Acknowledgements}

We thank the project staff at the Human Development Research Foundation, Islamabad, the Lady Health Worker Program in Swat District, Saidu Teaching Hospital, and the Institute of Psychiatry, WHO Collaborating Center for Mental Health, Rawalpindi, for their contributions. We also thank the Swat District health administration and PHC staff and physicians for their support and participation in the conduct of the study. Finally, we thank the participants and their families for their voluntary participation. The authors alone are responsible for the views expressed in this article and they do not necessarily represent the views, decisions or policies of the institutions with which they are affiliated. 


\section{Evidence before this study}

WHO guidelines for management of mental disorders in non-specialist settings (http://www.who.int/mental_health/mhgap/evidence/en/), revised in 2016, synthesised available evidence on psychological interventions for common mental disorders including depression, anxiety and post-traumatic stress disorder. The guidelines recommend a range of interventions for non-specialised health care settings including cognitive behavioural therapy, interpersonal therapy and stress management, delivered in individual or group formats. Supplementing the WHO evidence-review, a recent systematic review of psychological intervention for depression, anxiety and posttraumatic stress delivered by non-specialists in LMIC, searched 7 databases (CINAHL, MEDLINE, WHO's Global Index Medicus, PsychINFO, Web of Science, Cochrane CENTRAL, and EMBASE) from Jan 2012 to March 2016 as well as hand searching reference lists of selected systematic reviews. The 27 randomised trials reviewed demonstrated that individual and group interventions incorporating psychological strategies, including behavioural, interpersonal, emotional, and cognitive, delivered largely by non-specialists, had moderate to strong effects in reducing the burden of common mental disorder in these settings (pooled effect size $0.49(95 \%$ confidence interval $=0.36-0.62))$.

\section{Added value of this study}

Conflict-affected settings present a particular set of challenges to both implementation and robust evaluation of evidence-based interventions, especially those targeting vulnerable women. This study shows that local non-specialists, working in partnership with the primary care system, and supervised by experts from a distance, were able to successfully deliver a brief group psychological intervention incorporating behavioural and stress-management strategies to previously untreated women. A cRCT, with a high response rate at 3-months post-intervention, demonstrated strong intervention effects in reducing anxiety and depression in this population (effect size 0.58 ).

\section{Implications of all the available evidence}

Addressing the psychological sequelae of conflict is an essential element of reconstruction and rehabilitation. Building on existing evidence from LMIC, this feasible and effective brief group intervention likely has the potential for scale-up in post-conflict settings to reduce the burden from common mental disorder, especially in hard-to-access vulnerable women. 
614

615

616

617

618

619

620

621

622

623

624

625

626

627

628

629

630

631

632

633

634

635

636

637

638

639

640

641

642

643

644

645

646

647

648

649

650

651

652

653

654

655

656

657

658

659

660
1. Rothbart D, Korostelina K, Cherkaoui M. Civilians and Modern War: Armed Conflict and the Ideology of Violence. New York: Routledge, 2012.

2. Murthy RS, Lakshminarayana R. Mental health consequences of war: a brief review of research findings. World Psychiatry. 2006;5(1):25-30.

3. Charlson F, Flaxman A, Ferrari A, Vos T, Steel Z, Whiteford H. Post-traumatic stress disorder and major depression in conflict-affected populations: an epidemiological model and predictor analysis. Glob Ment Health. 2016;3:e4

4. Khan MN, Chiumento A, Dherani M, Bristow K, Sikander S, Rahman A. Psychological distress and its associations with past events in pregnant women affected by armed conflict in Swat, Pakistan: a cross sectional study. Confl Health. 2015;9(1):37.

5. Husain N, Chaudhry I, Afridi M, Tomenson B, Creed F. Life stress and depression in a tribal area of Pakistan. Br J Psychiatry. 2007;190(1):36-41.

6. World Health Organization. Scalable psychological interventions for people in communities affected by adversity: a new area of mental health and psychosocial work at WHO. 2017; http://apps.who.int/iris/bitstream/10665/254581/1/WHOMSD-MER-17.1-eng.pdf. Last accessed April 16, 2018.

7. World Health Organization. mhGAP intervention guide for mental, neurological and substance use disorders in non-specialized health settings: mental health Gap Action Programme (mhGAP) Version 2.0. Geneva: World Health Organization, 2016.

8. Singla DR, Kohrt BA, Murray LK, Anand A, Chorpita BF, Patel V. Psychological treatments for the world: Lessons from low-and middle-income countries. Annu Rev Clin Psychol. 2017;13:149-181.

9. van Ginneken N, Tharyan P, Lewin S, Rao GN, Meera S, Pian J, et al. Nonspecialist health worker interventions for the care of mental, neurological and substance-abuse disorders in low- and middle-income countries. Cochrane Database Syst Rev. 2013;11:CD009149.

10. Dawson KS, Bryant RA, Harper M, Tay AK, Rahman A, Schafer A, et al. Problem Management Plus (PM+): a WHO transdiagnostic psychological intervention for common mental health problems. World Psychiatry. 2015;14(3):354-357.

11. Rahman A, Hamdani SU, Awan NR, Bryant R, Dawson KS, Khan MF, et al. Effect of a multicomponent behavioural intervention in adults impaired by psychological distress in a conflict-affected area of Pakistan: a randomized clinical trial. JAMA. 2016;316(24):2609-2617.

12. Khan MN, Hamdani SU, Chiumento A, Dawson K, Bryant RA, Sijbrandij M, et al. Evaluating feasibility and acceptability of a group WHO trans-diagnostic intervention for women with common mental disorders in rural Pakistan: a cluster randomised controlled feasibility trial. Epidemiol Psychiatr Sci. 2017:1-11.

13. Bile K, Hafeez A, Chotani RA. Crisis in the Swat Valley of Pakistan: need for international action. Lancet. 2009;374(9683):23-24.

14. Din IU, Mumtaz Z, Ataullahjan A. How the Taliban undermined community healthcare in Swat, Pakistan. BMJ. 2012;344:e2093

15. Chiumento A, Hamdani SU, Khan MN, Dawson K, Bryant RA, Sijbrandij M et al. Evaluating effectiveness and cost-effectiveness of a group psychological intervention using cognitive behavioural strategies for women with common 
mental disorders in conflict-affected rural Pakistan: study protocol for a randomised controlled trial. Trials. 2017;18(1):190.

16. Minhas F, Mubbashar M. Validation of General Health Questionnaire (GHQ-12) in primary care settings of Pakistan. J Coll Physicians Surg Pak. 1996;6:133-136.

17. World Health Organization. Measuring health and disability; Manual for WHO Disability Assessment Schedule WHODAS 2.0. Geneva, Switzerland: WHO; 2010.

18. Zigmond AS, Snaith RP. The Hospital Anxiety and Depression Scale. Acta Psychiatr Scand. 1983;67(6):361-370.

19. Mumford DB, Tareen IA, Bajwa MA, Bhatti MR, Karim R. The translation and evaluation of an Urdu version of the Hospital Anxiety and Depression Scale. Acta Psychiatr Scand. 1991;83(2):81-85.

20. Puhan MA, Frey M, Buchi S, Schunemann HJ. The minimal important difference of the hospital anxiety and depression scale in patients with chronic obstructive pulmonary disease. Health Qual Life Outcomes.. 2008;6:46.

21. Blanchard EB, Jones-Alexander J, Buckley TC, Forneris CA. Psychometric properties of the PTSD Checklist (PCL). Behav Res Ther. 1996;34(8):669-673.

22. Ashworth M, Robinson, SI, Godfrey E, Melanie S; Evans C, Seed P, et al. Measuring mental health outcomes in primary care: the psychometric properties of a new patient-generated outcome measure, 'PSYCHLOPS' ('psychological outcome profiles'). Primary Care Mental Health. 2005;3(4):261-270.

23. Akhtar A, Rahman A, Husain M, Chaudhry IB, Duddu V, Husain N. Multidimensional scale of perceived social support: Psychometric properties in a South Asian population. J Obstet Gynaecol Res 2010, 36(4):845-851.

24. Kroenke K, Spitzer R, J. W. The PHQ-9: Validity of a brief depression severity measure. Journal of General Internal Medicine. 2001;16:606-613.

25. Ahmer S, Faruqui RA, Aijaz A. Psychiatric rating scales in Urdu: a systematic review. BMC Psychiatry. 2007;7:59.

26. Rahman A, Malik A, Sikander S, Roberts C, Creed F. Cognitive behaviour therapy-based intervention by community health workers for mothers with depression and their infants in rural Pakistan: a cluster-randomised controlled trial. Lancet. 2008;372(9642):902-9.

27. Huntley AL, Araya R, Salisbury C. Group psychological therapies for depression in the community: systematic review and meta-analysis. Br J Psychiat. 2012;200(3):184-190.

28. Tol WA, Barbui C, van Ommeren M. Management of acute stress, PTSD, and bereavement: WHO recommendations. JAMA. 2013 Aug 7;310(5):477-8.

29. Murray LK, Dorsey S, Bolton P, Jordans MJ, Rahman A, Bass J, et al. Building capacity in mental health interventions in low resource countries: an apprenticeship model for training local providers. Int J Ment Health Syst. 2011;5(1):30.

30. Martin P, Kumar S, Lizarondo L. Effective use of technology in clinical supervision. Internet Interv. 2017; 8:35-39

31. Wessells, M. G. Do no harm: Toward contextually appropriate psychosocial support in international emergencies. Am Psychol. 2009;64(8), 842-854.

32. Chiumento A, Khan MN, Rahman A, Frith L. Managing ethical challenges to mental health research in post-conflict settings. Dev World Bioeth. 2016;16(1):1528. 


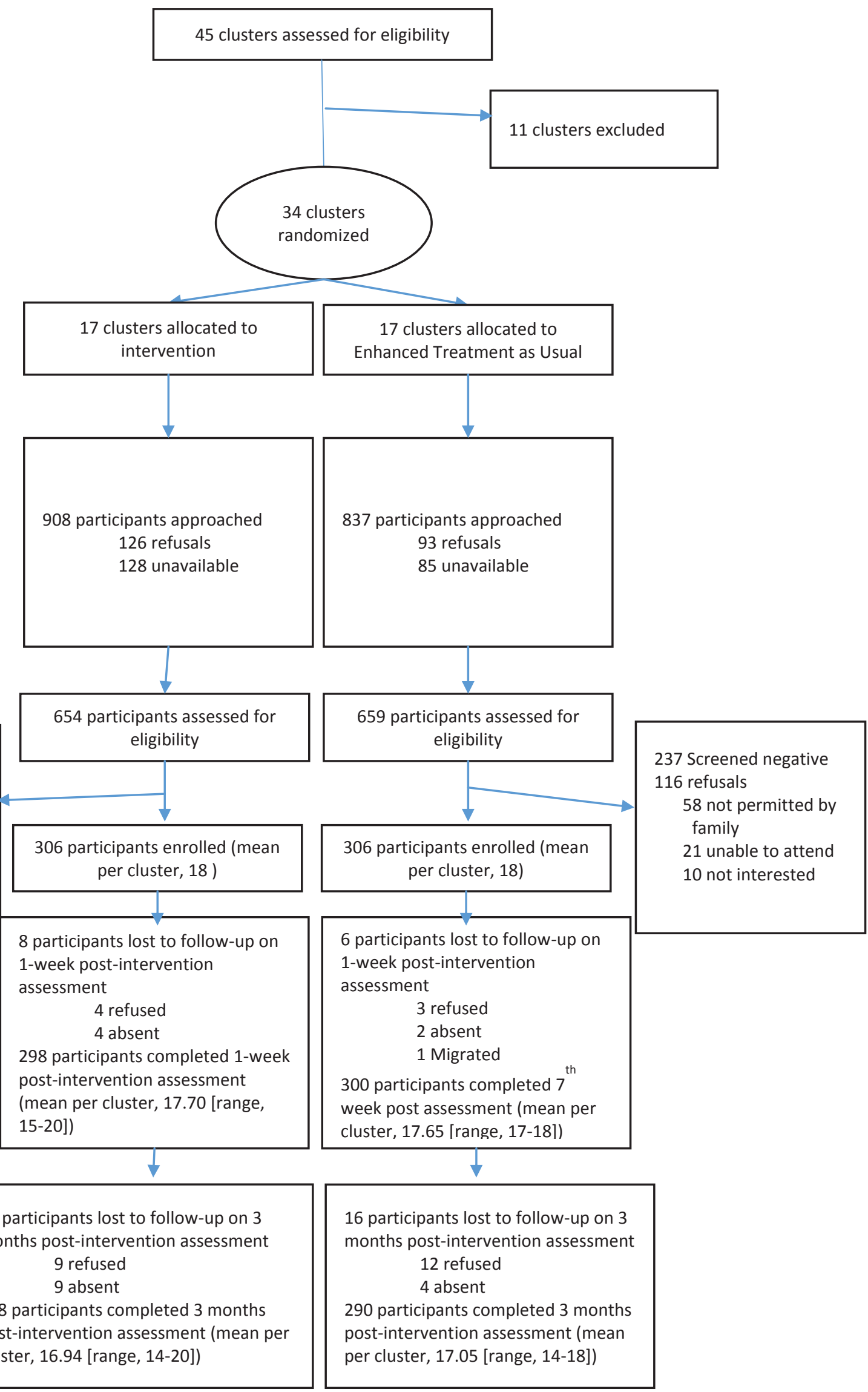

232 Screened negative 116 Refusals

55 not permitted by family

23 unable to attend 15 not interested

\section{6}

747

748

749

750

751

752

753

754

755

756

757

758

759

760

761

762

763

764
18 participants lost to follow-up on 3 months post-intervention assessment 9 refused 9 absent

288 participants completed 3 months post-intervention assessment (mean per cluster, 16.94 [range, 14-20])
17 clusters allocated to

Enhanced Treatment as Usual

237 Screened negative 16 refusals

58 not permitted by

21 unable to attend

10 not interested 


\begin{tabular}{|c|c|c|c|}
\hline Variables & $\begin{array}{l}\text { Total } \\
(\mathrm{N}=612)\end{array}$ & $\begin{array}{l}\text { Intervention group } \\
(\mathrm{N}=306)\end{array}$ & $\begin{array}{l}\text { Control group } \\
(\mathrm{N}=306)\end{array}$ \\
\hline Age & $36.26(9.87)$ & $37.35(10.50)$ & $35.19(9.11)$ \\
\hline \multicolumn{4}{|l|}{ Education } \\
\hline No schooling & $503(82.2 \%)$ & $248(81.0 \%)$ & $255(83.3 \%)$ \\
\hline Primary (6 years) & $51(8.3 \%)$ & $28(9.2 \%)$ & $23(7.5 \%)$ \\
\hline Middle ( 8 years) & $22(3.6 \%)$ & $12(3.9 \%)$ & $10(3.3 \%)$ \\
\hline Matriculate (10 years) & $18(3.0 \%)$ & $12(3.9 \%)$ & $6(2.0 \%)$ \\
\hline Intermediate ( 12 years $)$ & $9(1.5 \%)$ & $3(1.0 \%)$ & $6(2.0 \%)$ \\
\hline College and university (16 years) & $6(1.0 \%)$ & $1(0.3 \%)$ & $5(1.6 \%)$ \\
\hline Missing data & $3(0.5 \%)$ & $2(0.7 \%)$ & $1(0.3 \%)$ \\
\hline \multicolumn{4}{|l|}{ Work Status } \\
\hline Housewife & $517(84.3 \%)$ & $269(87.9 \%)$ & $248(81.0 \%)$ \\
\hline Self-employed (such as own business) & $14(2.3 \%)$ & $8(2.6 \%)$ & $6(2.0 \%)$ \\
\hline Paid work (such as sewing) & $63(10.3 \%)$ & $23(7.5 \%)$ & $40(13.1 \%)$ \\
\hline Non paid work (such as volunteer or charity) & $1(0.2 \%)$ & $1(0.3 \%)$ & $0(0 \%)$ \\
\hline Student & $3(0.5 \%)$ & $0(0 \%)$ & $3(1.0 \%)$ \\
\hline Unemployed & $11(1.8 \%)$ & $4(1.3 \%)$ & $7(2.3 \%)$ \\
\hline Other & $2(0.3 \%)$ & $0(0 \%)$ & $2(0.7 \%)$ \\
\hline Missing data & $1(0.2 \%)$ & $1(0.3 \%)$ & $0(0 \%)$ \\
\hline \multicolumn{4}{|l|}{ Family structure } \\
\hline Nuclear & $303(49.5 \%)$ & $156(51.0 \%)$ & $147(48.1 \%)$ \\
\hline Joint (woman sharing home with her in-laws) & $308(50.3 \%)$ & $150(49.0 \%)$ & $158(51.6 \%)$ \\
\hline Missing & $1(0.2)$ & $0(0 \%)$ & $1(0.3)$ \\
\hline Number of children & $4.72(2.30)$ & $4.84(2.45)$ & $4.61(2.15)$ \\
\hline
\end{tabular}


Table 2. Summary statistics and results from mixed model analysis of primary and secondary outcomes

\begin{tabular}{|c|c|c|c|c|c|c|c|c|}
\hline \multirow{3}{*}{$\begin{array}{c}\text { Primary and } \\
\text { secondary outcomes }\end{array}$} & \multirow[b]{3}{*}{ Visit } & \multicolumn{4}{|c|}{ Descriptive statistics } & \multicolumn{3}{|l|}{ Mixed model analysis } \\
\hline & & \multicolumn{2}{|c|}{ Intervention } & \multicolumn{2}{|c|}{ EUC } & \multirow{2}{*}{$\begin{array}{c}\text { Difference in LS } \\
\text { mean }(95 \% \mathrm{CI})\end{array}$} & \multirow[b]{2}{*}{ P-value } & \multirow{2}{*}{$\begin{array}{l}\text { Effect } \\
\text { size }^{a}\end{array}$} \\
\hline & & $\mathrm{N}$ & Mean (SD) & $\mathrm{N}$ & Mean (SD) & & & \\
\hline \multirow{3}{*}{$\begin{array}{l}\text { HADS total (Anxiety } \\
\text { and Depression) }\end{array}$} & Baseline & 306 & $21.08(6.69)$ & 305 & $21.83(7.30)$ & & & \\
\hline & $\begin{array}{l}\text { 1-week post- } \\
\text { intervention }\end{array}$ & 300 & $10.58(8.05)$ & 298 & $17.00(8.30)$ & $-6.30(-8.89,-3.70)$ & $<.0001$ & 0.77 \\
\hline & $\begin{array}{l}3 \text { months post- } \\
\text { intervention }\end{array}$ & 288 & $10.01(7.54)$ & 289 & $14.75(8.11)$ & $-4.53(-7.13,-1.92)$ & 0.0007 & 0.58 \\
\hline \multirow[t]{3}{*}{ HADS Anxiety } & Baseline & 306 & $11.46(3.99)$ & 305 & $11.71(3.95)$ & & & \\
\hline & $\begin{array}{l}\text { 1-week post- } \\
\text { intervention }\end{array}$ & 300 & $5.84(4.58)$ & 298 & $8.99(4.70)$ & $-3.14(-4.64,-1.63)$ & $<.0001$ & 0.68 \\
\hline & $\begin{array}{l}3 \text { months post- } \\
\text { intervention }\end{array}$ & 288 & $5.43(4.18)$ & 289 & $8.02(4.69)$ & $-2.52(-4.04,-1.01)$ & 0.0011 & 0.57 \\
\hline \multirow[t]{3}{*}{ HADS Depression } & Baseline & 306 & $9.62(3.64)$ & 305 & $10.12(4.18)$ & & & \\
\hline & $\begin{array}{l}\text { 1-week post- } \\
\text { intervention }\end{array}$ & 300 & $4.74(3.95)$ & 298 & $8.01(4.21)$ & $-3.20(-4.35,-2.05)$ & $<.0001$ & 0.78 \\
\hline & $\begin{array}{l}3 \text { months post- } \\
\text { intervention }\end{array}$ & 288 & $4.59(3.87)$ & 289 & $6.73(3.91)$ & $-2.04(-3.19,-0.88)$ & 0.0006 & 0.52 \\
\hline \multirow[t]{3}{*}{ WHO DAS } & Baseline & 306 & $28.41(6.71)$ & 306 & $30.30(7.68)$ & & & \\
\hline & $\begin{array}{l}\text { 1-week post- } \\
\text { intervention }\end{array}$ & 300 & $19.68(7.11)$ & 300 & $24.84(7.34)$ & $-4.67(-7.15,-2.19)$ & 0.0002 & 0.65 \\
\hline & $\begin{array}{l}3 \text { months post- } \\
\text { intervention }\end{array}$ & 288 & $19.36(6.64)$ & 289 & $22.82(7.35)$ & $-2.90(-5.39,-0.42)$ & 0.0222 & 0.41 \\
\hline \multirow[t]{3}{*}{ PCL-5 } & Baseline & 306 & $18.67(11.57)$ & 306 & $21.35(12.02)$ & & & \\
\hline & $\begin{array}{l}\text { 1-week post- } \\
\text { intervention }\end{array}$ & 300 & $8.66(9.17)$ & 299 & $12.41(8.29)$ & $-3.44(-6.15,-0.73)$ & 0.0128 & 0.39 \\
\hline & $\begin{array}{l}3 \text { months post- } \\
\text { intervention }\end{array}$ & 288 & $9.75(7.11)$ & 290 & $12.33(8.57)$ & $-2.16(-4.88,0.56)$ & 0.1188 & 0.28 \\
\hline \multirow[t]{3}{*}{ MSPSS } & Baseline & 306 & $50.86(17.05)$ & 306 & $50.71(18.43)$ & & & \\
\hline & $\begin{array}{l}\text { 1-week post- } \\
\text { intervention }\end{array}$ & 300 & $54.13(17.40)$ & 299 & $50.70(18.22)$ & $3.47(-1.33,8.28)$ & 0.1560 & 0.20 \\
\hline & $\begin{array}{l}3 \text { months post- } \\
\text { intervention }\end{array}$ & 288 & $57.00(18.31)$ & 290 & $55.05(18.73)$ & $1.96(-2.87,6.78)$ & 0.4259 & 0.11 \\
\hline \multirow[t]{3}{*}{ PHQ-9 } & Baseline & 306 & $10.11(4.13)$ & 306 & $11.19(4.32)$ & & & \\
\hline & $\begin{array}{l}\text { 1-week post- } \\
\text { intervention }\end{array}$ & 300 & $5.74(4.83)$ & 299 & $9.69(4.95)$ & $-3.67(-5.15,-2.19)$ & $<.0001$ & 0.75 \\
\hline & $\begin{array}{l}3 \text { months post- } \\
\text { intervention }\end{array}$ & 288 & $5.77(4.16)$ & 290 & $7.79(4.65)$ & $-1.67(-3.16,-0.19)$ & 0.0271 & 0.38 \\
\hline \multirow[t]{3}{*}{ PSYCHLOPS } & Baseline & 306 & $13.92(3.18)$ & 306 & $14.65(2.45)$ & & & \\
\hline & $\begin{array}{l}\text { 1-week post- } \\
\text { intervention }\end{array}$ & 300 & $7.21(4.72)$ & 300 & $11.24(4.17)$ & $-3.84(-5.49,-2.19)$ & $<.0001$ & 0.86 \\
\hline & $\begin{array}{l}3 \text { months post- } \\
\text { intervention }\end{array}$ & 288 & $8.10(5.66)$ & 290 & $10.39(5.48)$ & $-2.07(-3.73,-0.41)$ & 0.0147 & 0.37 \\
\hline
\end{tabular}

771 Abbreviations. EUC = Enhanced usual care; LS = Least Square; HADS = Hospital Anxiety and

772 Depression Scales (subscale score range: 0-21; higher scores indicate elevated anxiety or depression,

773 respectively); WHODAS $=$ WHO Disability Assessment Schedule (total score range: 0-48; higher

774 scores indicate more severe impairment); PCL-5 = Posttraumatic Stress Disorder Checklist (total score

775 range: 0-80; higher scores indicate more severe PTSD severity); MSPSS = Multidimensional scale of

776 perceived social support PHQ-9 = Patient Health Questionnaire (total score range: 0-27; higher scores

777 indicate more severe depression; PSYCHLOPS = Psychological Outcomes Profiles (total score range:

$778 \quad 0-20$; higher scores indicate poorer outcome);

779 a Effect size was calculated by the difference in least square means between intervention and EUC from

780 mixed model divided by the pooled standard deviation at each visit 
782 Table 3. Summary of mixed model analysis of primary and secondary outcomes: covariate

783 adjusted analysis*

\begin{tabular}{|c|c|c|c|c|c|c|c|}
\hline \multicolumn{6}{|c|}{ Descriptive statistics } & \multicolumn{2}{|c|}{ Mixed model analysis } \\
\hline \multirow{2}{*}{$\begin{array}{l}\text { Primary and secondary } \\
\text { outcomes }\end{array}$} & \multirow[b]{2}{*}{ Visit } & \multicolumn{2}{|c|}{ Intervention } & \multicolumn{2}{|l|}{ EUC } & \multirow{2}{*}{$\begin{array}{l}\text { Difference in LS } \\
\text { mean }(95 \% \mathrm{CI})\end{array}$} & \multirow[b]{2}{*}{ P-value } \\
\hline & & $\mathrm{N}$ & Mean (SD) & $\mathrm{N}$ & Mean (SD) & & \\
\hline \multirow{3}{*}{$\begin{array}{l}\text { HADS Anxiety and } \\
\text { Depression }\end{array}$} & Baseline & 306 & $21.08(6.69)$ & 305 & $21.83(7.30)$ & & \\
\hline & $\begin{array}{l}1 \text { week post- } \\
\text { intervention }\end{array}$ & 300 & $10.58(8.05)$ & 298 & $17.00(8.30)$ & $-5.78(-8.16,-3.41)$ & <.0001 \\
\hline & $\begin{array}{l}3 \text { months post- } \\
\text { intervention }\end{array}$ & 288 & $10.01(7.54)$ & 289 & $14.75(8.11)$ & $-4.03(-6.42,-1.65)$ & 0.0009 \\
\hline \multirow[t]{3}{*}{ HADS Anxiety } & Baseline & 306 & $11.46(3.99)$ & 305 & $11.71(3.95)$ & & \\
\hline & $\begin{array}{l}1 \text { week post- } \\
\text { intervention }\end{array}$ & 300 & $5.84(4.58)$ & 298 & $8.99(4.70)$ & $-2.83(-4.26,-1.40)$ & 0.0001 \\
\hline & $\begin{array}{l}3 \text { months post- } \\
\text { intervention }\end{array}$ & 288 & $5.43(4.18)$ & 289 & $8.02(4.69)$ & $-2.23(-3.66,-0.80)$ & 0.0023 \\
\hline \multirow[t]{3}{*}{ HADS Depression } & Baseline & 306 & $9.62(3.64)$ & 305 & $10.12(4.18)$ & & \\
\hline & $\begin{array}{l}1 \text { week post- } \\
\text { intervention }\end{array}$ & 300 & 4.74(3.95) & 298 & $8.01(4.21)$ & $-2.94(-4.00,-1.88)$ & k.0001 \\
\hline & $\begin{array}{l}3 \text { months post- } \\
\text { intervention }\end{array}$ & 288 & $4.59(3.87)$ & 289 & $6.73(3.91)$ & $-1.79(-2.86,-0.72)$ & 0.0010 \\
\hline \multirow[t]{3}{*}{ WHO DAS } & Baseline & 306 & $28.41(6.71)$ & 306 & $30.30(7.68)$ & & \\
\hline & $\begin{array}{l}1 \text { week post- } \\
\text { intervention }\end{array}$ & 300 & $19.68(7.11)$ & 300 & $24.84(7.34)$ & $-4.52(-7.02,-2.01)$ & 0.0004 \\
\hline & $\begin{array}{l}3 \text { months post- } \\
\text { intervention }\end{array}$ & 288 & $19.36(6.64)$ & 289 & $22.82(7.35)$ & $-2.74(-5.25,-0.24)$ & 0.0320 \\
\hline \multirow[t]{3}{*}{ PCL-5 } & Baseline & 306 & $18.67(11.57)$ & 306 & $21.35(12.02)$ & & \\
\hline & $\begin{array}{l}1 \text { week post- } \\
\text { intervention }\end{array}$ & 300 & $8.66(9.17)$ & $299 x$ & $21.35(12.02)$ & $-3.17(-5.77,-0.58)$ & 0.0167 \\
\hline & $\begin{array}{l}3 \text { months post- } \\
\text { intervention }\end{array}$ & 288 & $9.75(7.11)$ & 290 & $12.33(8.57)$ & $-1.91(-4.51,0.70)$ & 0.1508 \\
\hline \multirow[t]{3}{*}{ MSPSS } & Baseline & 306 & $50.86(17.05)$ & 306 & $50.71(18.43)$ & & \\
\hline & $\begin{array}{l}1 \text { week post- } \\
\text { intervention }\end{array}$ & 300 & $54.13(17.40)$ & 299 & $50.70(18.22)$ & $1.66(-3.38,6.70)$ & 0.5176 \\
\hline & $\begin{array}{l}3 \text { months post- } \\
\text { intervention }\end{array}$ & 288 & $57.00(18.31)$ & 290 & $55.05(18.73)$ & $-3.62(-5.23,-2.01)$ & 0.0001 \\
\hline \multirow[t]{3}{*}{ PHQ-9 } & Baseline & 306 & $10.11(4.13)$ & 306 & $11.19(4.32)$ & & \\
\hline & $\begin{array}{l}1 \text { week post- } \\
\text { intervention }\end{array}$ & 300 & $5.74(4.83)$ & 299 & $9.69(4.95)$ & $-3.51(-4.95,-2.07)$ & $<.0001$ \\
\hline & $\begin{array}{l}3 \text { months post- } \\
\text { intervention }\end{array}$ & 288 & $5.77(4.16)$ & 290 & $7.79(4.65)$ & $-1.52(-2.96,-0.07)$ & 0.0396 \\
\hline \multirow[t]{3}{*}{ PSYCHLOPS } & Baseline & 306 & $13.92(3.18)$ & 306 & $14.65(2.45)$ & & \\
\hline & $\begin{array}{l}1 \text { week post- } \\
\text { intervention }\end{array}$ & 300 & $7.21(4.72)$ & 300 & $11.24(4.17)$ & $-3.62(-5.23,-2.01)$ & $<.0001$ \\
\hline & $\begin{array}{l}3 \text { months post- } \\
\text { intervention }\end{array}$ & 288 & $8.10(5.66)$ & 290 & $10.39(5.48)$ & $-1.86(-3.47,-0.24)$ & 0.0242 \\
\hline
\end{tabular}

784

785 *Adjusted for age and baseline HADS and WHODAS scores

786

787

788

789 


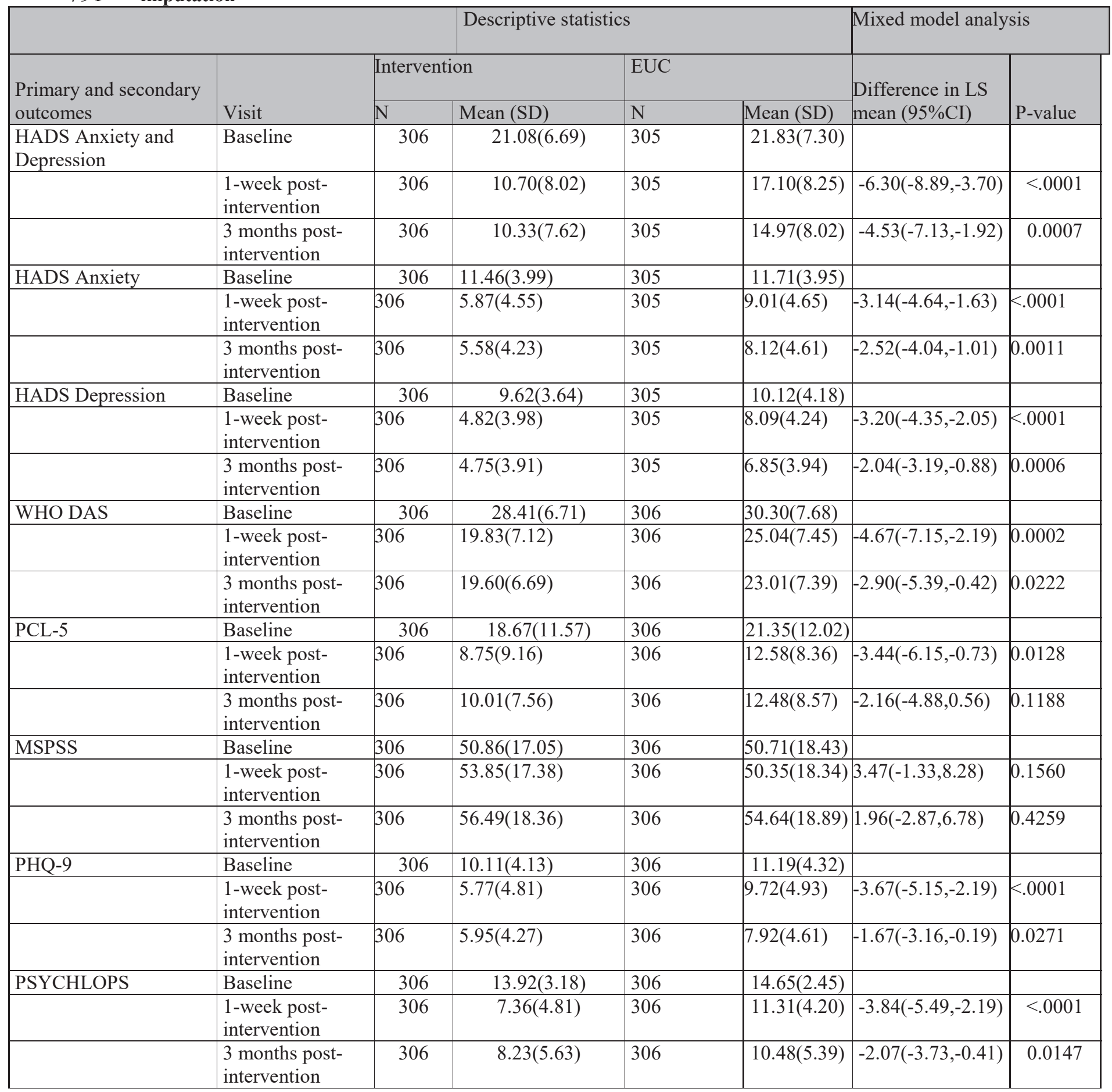

793 LOCF=Last observation carried forward 
Table 5. Summary of mixed model analysis of primary outcome (HADS total anxiety and

depression): subgroup analysis on baseline age and initial severity

\begin{tabular}{|c|c|c|c|c|c|c|c|}
\hline \multirow[b]{2}{*}{ Variable } & \multirow[b]{2}{*}{ Subgroup } & \multirow[b]{2}{*}{ Visit } & \multicolumn{2}{|c|}{$\begin{array}{l}\text { Descriptive statistics } \\
\quad \mathrm{N} \text {, mean(SD) }\end{array}$} & \multicolumn{3}{|c|}{ Mixed model result } \\
\hline & & & Intervention & $\mathrm{EU}$ & $\begin{array}{c}\text { Difference in LS } \\
\text { mean }(95 \% \mathrm{CI})\end{array}$ & P-value & $\begin{array}{l}\text { P-value from } \\
\text { interaction test }\end{array}$ \\
\hline Age group & $<35$ year & $\begin{array}{l}1 \text { week post- } \\
\text { intervention }\end{array}$ & $118,-10.53(9.38)$ & $138,-5.10(9.55)$ & $-5.84(-8.58,-3.09)$ & $<.0001$ & 0.8500 \\
\hline & & $\begin{array}{l}3 \text { months } \\
\text { post- } \\
\text { intervention }\end{array}$ & $111,-11.32(9.45)$ & $136,-6.69(9.22)$ & $-4.90(-7.66,-2.13)$ & 0.0006 & \\
\hline & $\geq 35$ year & $\begin{array}{l}1 \text { week post- } \\
\text { intervention }\end{array}$ & $\begin{array}{c}182,- \\
10.63(10.10\end{array}$ & $160,-4.63(7.92)$ & $-6.78(-9.73,-3.82)$ & $<.0001$ & \\
\hline & & $\begin{array}{l}3 \text { months } \\
\text { post- } \\
\text { intervention }\end{array}$ & $177,-10.92(9.29)$ & $153,-7.16(9.77)$ & $-4.43(-7.39,-1.46)$ & 0.0036 & \\
\hline WHODAS & $<29$ & $\begin{array}{l}1 \text { week post- } \\
\text { intervention }\end{array}$ & $\begin{array}{c}164,- \\
11.23(10.71\end{array}$ & $135,-4.78(10.14)$ & $-6.20(-9.18,-3.23)$ & $<.0001$ & 0.4109 \\
\hline & & $\begin{array}{l}3 \text { months } \\
\text { post- } \\
\text { intervention }\end{array}$ & $156,-12.19(9.55)$ & $133,-7.33(10.39)$ & $-4.63(-7.62,-1.64)$ & 0.0025 & \\
\hline & $\geq 29$ & $\begin{array}{l}1 \text { week post- } \\
\text { intervention }\end{array}$ & $136,-9.82(8.57)$ & $163,-4.91(7.33)$ & $-6.17(-8.91,-3.42)$ & $<.0001$ & \\
\hline & & $\begin{array}{l}3 \text { months } \\
\text { post- } \\
\text { intervention }\end{array}$ & $132,-9.77(8.94)$ & $156,-6.60(8.69)$ & $-4.12(-6.88,-1.35)$ & 0.0037 & \\
\hline PHQ & $<11$ & $\begin{array}{l}1 \text { week post- } \\
\text { intervention }\end{array}$ & $165,-10.07(9.54)$ & $133,-4.44(9.50)$ & $-5.42(-8.33,-2.50)$ & 0.0003 & 0.1571 \\
\hline & & $\begin{array}{l}3 \text { months } \\
\text { post- } \\
\text { intervention }\end{array}$ & $161,-10.24(9.09)$ & $131,-6.52(10.16)$ & $-3.58(-6.51,-0.66)$ & 0.0165 & \\
\hline & $\geq 11$ & $\begin{array}{l}1 \text { week post- } \\
\text { intervention }\end{array}$ & $\begin{array}{c}135,- \\
11.22(10.12\end{array}$ & $165,-5.18(8.01)$ & $-5.95(-8.66,-3.24)$ & $<.0001$ & \\
\hline & & $\begin{array}{l}3 \text { months } \\
\text { post- } \\
\text { intervention }\end{array}$ & $127,-12.13(9.57)$ & $158,-7.28(8.94)$ & $-4.37(-7.11,-1.63)$ & 0.0018 & \\
\hline
\end{tabular}

